\title{
O preconceito contra a mulher entre trabalhadores da Atenção Primária em Saúde
}

\author{
Sexism against women among primary healthcare workers
}

\author{
Marcos Mesquita Filho ${ }^{1}$ \\ Thaline Figueiredo Marques ${ }^{2}$ \\ Ana Beatriz Cavalcanti Rocha ${ }^{2}$ \\ Suellen Ramos de Oliveira ${ }^{2}$ \\ Maíra Barbosa Brito ${ }^{2}$ \\ Camila Claudiano Quina Pereira ${ }^{1}$
}

${ }^{1}$ Mestrado em Bioética, Universidade do Vale do Sapucaí (Univas). Av. Pref. Tuany Toledo 470, Fátima. 37554-210 Pouso Alegre MG Brasil. mesquita.filho@uol.com.br ${ }^{2}$ Faculdade de Ciências da Saúde, Univas. Pouso Alegre MG Brasil.

\begin{abstract}
The objective of this study was to research the existence of sexism against women among primary healthcare (PHC) workers and to identify associated factors. This was a cross-sectional study in which 163 PHC professionals of both sexes participated, all of whom were aged over 18 and had completed their primary or secondary education. The Gender Stereotyping and Ambivalent Sexism Inventory questionnaires were used. The average scores were more than $50 \%$ of the maximum score: Gender Stereotyping - 53.8\%, hostile sexism $58.2 \%$, benevolent sexism $-64.1 \%$. The average scores stratified by sociodemographic variables were higher. Significant differences in the hostile sexism score were found for sex (men scored higher than women), religion (higher scores for evangelical Christians) and among those who drank alcohol. For benevolent sexism, differences were found for schooling (greater scores for those who had only completed their primary education), religion (higher scores for evangelical Christians and Catholics) and area of work (greater for those working in general services). The stratification of the Gender Stereotyping scores did not point to significant differences. Sexist prejudice was found to exist for hostile sexism, benevolent sexism and gender stereotyping. This finding could have a negative influence on the service-user relationship, leading to greater inequities in health as a result of gender inequality.
\end{abstract}

Key words Women's health, Sexism, Health inequality, Healthcare staff, Health services
Resumo O objetivo deste trabalho foi pesquisar a existência de preconceitos contra a mulher entre trabalhadores da Atenção Primária em Saúde e identificar fatores associados. Estudo transversal que teve a participação de 163 profissionais de APS. Foram utilizados os questionários Estereótipos de Gênero (EG) e o Inventário do Sexismo Ambivalente. Pesquisou-se indivíduos dos dois sexos, com mais de 18 anos e escolaridade básica ou média. Os escores médios tinham valores acima de $50,0 \%$ do valor máximo: $E G-53,8 \%$, Sexismo Hostil-58,2\%; Sexismo Benévolo-64,1\%. As médias estratificadas por variáveis sociodemográficas eram elevadas. Foram encontradas diferenças significantes por sexo (masculino maior que feminino), religiões (maior nos evangélicos) e nos que usavam bebidas alcoólicas, no Sexismo Hostil. No Sexismo Benévolo houve diferenças por escolaridade (maior no nível básico), religião (maior nos evangélicos e católicos) e atividade exercida (maior em serviços gerais). Estratificando EG não se encontrou diferenças significantes. Preconceitos sexistas hostis, benevolentes e estereótipos de gêenero foram detectados. Esse achado pode influir negativamente na relação serviço-usuárias agravando as iniquidades em saúde geradas pelas desigualdades entre gêneros.

Palavras-chave Saúde da mulher, Sexismo, Desigualdades em saúde, Pessoal de saúde, Serviços de saúde 


\section{Introdução}

A violência contra a mulher, pela gravidade de suas consequências físicas, mentais e sociais, por sua elevada morbimortalidade, que, segundo a OMS, atinge proporções epidêmicas ${ }^{1}$, pela forte carga de sofrimento que provoca, pelos altos custos gerados ao sistema de saúde é considerada importante problema de saúde pública. Ela é, em grande parte, motivada por preconceitos e discriminação de gênero, que interferem na definição, elaboração e execução de estratégias efetivas para seu equacionamento ${ }^{2}$. Podem ocasionar situações indesejáveis nas práticas dos serviços de saúde. A Política Nacional de Atenção Integral à Saúde da Mulher destaca, inclusive, que "as questões de gênero devem ser consideradas como um dos determinantes da saúde na formulação das políticas públicas"3.

A identidade de gênero implica na percepção que se tem sobre ser homem ou mulher, ou seja, como a pessoa se reconhece, conforme os atributos e papéis sociais que são atribuídos ao gênero masculino e feminino. Trata-se de uma construção social e cultural, sendo distinta da de sexo, que corresponde à condição biológica, no qual a anatomia do corpo irá definir o sexo masculino ou feminino ${ }^{4}$.

Compreende-se como estereótipo "um processo de formação de impressão, que constitui um conjunto de avaliações afetivas, morais e instrumentais, elaboradas em relação a um indivíduo. Esse conjunto possui a capacidade de orientar o percebedor em suas relações com o meio social"s. Já sexismo é "um conjunto de estereótipos quanto à aparência, atos, habilidades, emoções e papel apropriado na sociedade, de acordo com o gênero. Apesar de também estereotipar o homem, mais frequentemente reflete preconceitos contra o gênero feminino" 6 . O sexismo ocorre em dimensões ambivalentes: o hostil e o benévolo. O primeiro é a demonstração do preconceito com as mulheres de maneira explícita, "evidenciando crenças e práticas típicas de pessoas que consideram as mulheres inferiores aos homens, bem como refletindo antipatia e intolerância em relação ao seu papel como figura de poder e decisão". Já o segundo se expressa por atitudes aparentemente não preconceituosas, manifestas por um tom subjetivamente positivo, que define para a mulher uma identidade dependente, frágil, sensível, que necessita de amparo e atenção do homem ${ }^{7}$. Estas manifestações do preconceito se associam a fatores como gênero ${ }^{8,9}$, à escolaridade $^{10,11}$, ao apego ao conservadorismo, à religio- sidade cristã ${ }^{12}$, ao consumo de bebidas alcoólicas e drogas ilegais ${ }^{13}$.

Concepções sexistas e de estereótipos de gênero entre os profissionais de saúde podem orientar práticas discriminativas e preconceituosas. Preconceitos arraigados e a reiteração das desigualdades, relacionados à construção das identidades de gênero, podem ser evidenciados no exercício cotidiano das equipes de saúde 5 . Essas construções se refletem na privação da atenção à saúde das mulheres, prejudicando o seu acolhimento e cuidados essenciais, o que dificulta o zelo integral das equipes às usuárias7. As identidades de gênero determinam, além de atitudes do profissional, seu modo de enfrentar e agir perante os problemas. É importante ressaltar que elas resultam de um processo histórico e ideológico, que tem a figura masculina como referência central em toda a sociedade ${ }^{5}$. "Diferenças desnecessárias, injustas e evitáveis entre homens e mulheres em relação às oportunidades de desfrutar a saúde $\mathrm{e}$ as probabilidades de adoecer, descapacitar-se ou morrer por causas preveníveis" se incluem nas desigualdades entre os gêneros ${ }^{14}$.

Da mesma maneira que diferentes populações estão expostas a variados tipos e graus de risco, mulheres e homens, em função da organização social das relações de gênero, também estão expostos a padrões distintos de sofrimento, adoecimento e morte. A mulher encontra barreiras e iniquidades no acesso ao sistema de saúde. São comuns as dificuldades para obtenção de suporte para métodos contraceptivos, para a atenção pré-natal e puerpério ${ }^{15}$. Também nas situações de violências, tanto as de origem familiar como as provenientes de outras fontes, os serviços de saúde, na maioria das vezes, não costumam ser capazes de apresentar respostas adequadas ${ }^{5}$. Não é incomum que nos casos de violência contra a mulher, "a vítima seja considerada culpada pela agressão e o preconceito entre os profissionais de saúde promova uma nova ofensa à mulher"16. Os trabalhadores de saúde, notadamente nas situações em que a mulher é vítima de violência, devem exercer suas atividades com o emprego de procedimentos adequados para a sua atenção, garantindo a confidencialidade e $\mathrm{o}$ acesso a serviços especializados, físicos, mentais e jurídicos ${ }^{1}$. Além disto, existem estudos que mostram que o atendimento hospitalar das pessoas do sexo feminino apresenta iniquidades em relação ao do homem tanto em relação à indicação de procedimentos, como na qualidade da execução dos mesmos ${ }^{1,17,18}$.

O Sistema Único de Saúde (SUS) considera que os serviços da Estratégia Saúde da Família 
(ESF) são a porta de entrada do Sistema. Busca-se a construção de laços entre profissionais e usuários a partir do estabelecimento de territórios com população adscrita. Pelo estreitamento deste relacionamento vêm à tona situações, que fazem parte daquelas mediadas pela saúde e que outrora eram omitidas, como é o caso da violência doméstica ${ }^{19}$. Esta, apesar de poder causar danos a todos os componentes da família, tem na mulher sua principal vítima ${ }^{20}$. Pelas diretrizes do SUS, são os serviços de Atenção Primária à Saúde (APS) que devem ter o primeiro contato com as situações de violência contra a mulher. Diante disto, é imprescindível que se compreenda a percepção dos profissionais de saúde da construção social da identidade de gênero e da violência contra a mulher, para que suas ações em saúde possam ser adequadas e resolutivas. A detecção de sexismo e de outros estereótipos e preconceitos junto a trabalhadores de saúde, a compreensão de seus determinantes, são fundamentais para que haja melhor acolhimento e equacionamento das necessidades de saúde da mulher pelos profissionais de saúde. A presença de sexismo e estereótipos de gênero por parte dos profissionais da ESF poderá agravar, ao invés de obter ações integrais humanizadas e resolutivas, os casos da violência contra a mulher.

O objetivo deste trabalho foi o de pesquisar a existência de preconceitos contra a mulher em trabalhadores da Atenção Primária em Saúde e identificar fatores a eles associados.

\section{Métodos}

\section{Delineamento}

O estudo foi de natureza quantitativa, exploratório, transversal, analítico.

\section{Local}

Equipes municipais de Saúde da Família, do município de Pouso Alegre, MG. Trata-se de município de médio porte situado na região sul de Minas Gerais, com uma população estimada em 140.000 habitantes. Os serviços de APS estudados correspondiam a 19 unidades, que contavam com 252 profissionais, cobrindo em média 47,0\% da população.

\section{População de estudo e amostra}

Trabalhou-se com o universo dos trabalhadores da ESF, selecionados a partir dos seguintes critérios de elegibilidade: ser funcionário municipal, estar lotado em equipe da ESF, exercer função num serviço de saúde, ter contato com o público, possuir escolaridade fundamental ou média, não estar desfrutando de nenhum tipo de afastamento (por problemas de saúde, para tratar de questões particulares, por aposentadoria, etc.) e concordar em participar do estudo. Não participaram os trabalhadores de nível superior, que serão estudados numa segunda etapa deste trabalho. A amostra foi composta por 163 profissionais que correspondiam a $64,7 \%$ do pessoal que atuava no setor $(n=252)$. Não fizeram parte da pesquisa 89 indivíduos, sendo 17 por recusas. Os demais 72 não participaram por não cumprirem os critérios de elegibilidade ou porque não foram localizados.

\section{Instrumentos}

Foram utilizados três instrumentos para a coleta de informações. Inicialmente, foi aplicado um protocolo de dados sociodemográficos e de saúde. O segundo foi o questionário Gender Stereotyping, de domínio público criado por Gunter e Wober ${ }^{21}$ validado por Foshee e Baumann ${ }^{22}$, com versão brasileira desenvolvida por Eufrásio ${ }^{23}$, que mensura estereótipos de gênero no contexto de relações e responsabilidades. É composto de sete itens fechados, com quatro opções de respostas, que recebem pontuações diferentes quando selecionadas: Concordo totalmente (quatro pontos); Concordo (três pontos); Discordo (dois pontos); Discordo totalmente (um ponto). A questão de número sete tem a contagem de pontos invertida. Quanto mais alta for a pontuação final, maior o indicativo de atitude estereotipada. O maior escore possível é de 28 pontos.

O terceiro instrumento foi o Inventário de Sexismo Ambivalente, desenvolvido originalmente por Glick et al. ${ }^{24}$, adaptado e validado para o Brasil por Formiga et al. ${ }^{25}$. Composto de 22 itens avalia preconceitos assumidos em duas dimensões do sexismo: hostil (11 questões) e benevolente (11 questões). Para respondê-los, a pessoa deve indicar seu grau de discordância ou de concordância com o conteúdo expresso, utilizando uma escala de cinco pontos, tipo Likert, com os seguintes tópicos: 1 = Discordo totalmente; 2 = Discordo; 3 = Indeciso; 4 = Concordo e 5 = Concordo totalmente. Os itens se apresentam ou por afirmativas positivas, ou por outras de cunho sexista. Quanto mais elevado o escore, maior o nível de sexismo. A pontuação mais alta possível é de 55 pontos por dimensão. As esca- 
las não apresentam um ponto de corte definido. Também neste instrumento, quanto mais elevados os escores, maiores são os preconceitos.

\section{Procedimentos}

Os pesquisadores se deslocaram até os serviços municipais de APS e entraram em contato com os participantes da pesquisa. Em cada uma das Unidades realizaram reuniões onde explicaram os objetivos do trabalho e a metodologia aplicada. Em seguida, convidaram os profissionais que podiam ser incluídos na pesquisa a participar do estudo. Aqueles que aceitaram compuseram a amostra. A manifestação desta concordância foi explicitada pela assinatura do Termo de Consentimento de Livre e Esclarecido (TCLE). No passo seguinte foi efetuada a leitura dos questionários e se questionou sobre o entendimento de cada um deles. Quando ocorria qualquer dúvida, o pesquisador lia novamente a(s) questão(ões) não compreendida(s) até que o indivíduo manifestasse seu entendimento. Não era explicado o sentido de nenhuma das perguntas, para que a resposta não fosse influenciada pelo pesquisador. Quando não restasse mais nenhuma dúvida, os questionários eram auto respondidos na seguinte ordem: $1^{\mathrm{o}}$ - Questionário sociodemográfico e de saúde; $2^{\circ}$ - Estereótipos de Gêneros; 3o- Inventário do Sexismo Ambivalente. A aplicação dos instrumentos era realizada em sala isolada, tranquila, sem interferência de terceiros. No final do trabalho, o pesquisador certificava se todas as questões tinham sido respondidas e solicitava ao respondente que houvesse deixado qualquer item sem preenchimento, para completá-lo.

\section{Banco de dados e análise estatística}

Os questionários foram tabulados em um banco de dados construído no programa Microsoft Excel. Para a análise estatística usou-se o SPSS 17. A descrição de variáveis quantitativas foi efetuada por medidas de tendência central (média, mediana) e de dispersão (desvio padrão). As variáveis categóricas foram descritas por proporções. Os procedimentos analíticos para medidas de tendência central, quando as variáveis se distribuíam de maneira normal, foram o teste t ou a análise de variância (ANOVA). No caso de variáveis não paramétricas, aplicaram-se os testes de Mann-Whitney ou de Kruskal-Wallis. A adesão à normalidade foi testada pelo teste de Kolmogorov-Smirnov. Considerou-se estatisticamente significante $\mathrm{p} \leq 0,05$.

\section{Procedimentos éticos}

Essa pesquisa seguiu as diretrizes da resolução 466/2012 do Conselho Nacional de Saúde e foi aprovada pelo Comitê de Ética em Pesquisa da Universidade do Vale do Sapucaí.

\section{Resultados}

A amostra era composta principalmente por mulheres $(89,0 \%)$, sendo que $58,9 \%$ tinha mais de 35 anos. A maior parte dos trabalhadores havia cursado o ensino médio ou técnico $(78,5 \%)$. Se declararam brancos $79,8 \%$ do total da amostra. Quanto à religião, 70,6\% eram católicos. Foram $77,9 \%$ os que informaram ter companheiro (a). A maior parte dos trabalhadores $(54,0 \%)$ morava num bairro diferente daquele onde se situava a Unidade de Saúde, 52,1\% residiam com seus cônjuges e $20,9 \%$ com os pais. A maioria dos profissionais exerciam funções na área de atenção à saúde $(69,9 \%)$. Os demais, trabalhavam na área administrativa ou como auxiliares de serviço. Todos tinham contato direto com os usuários do serviço. A renda familiar de $94,5 \%$ era de no máximo 5 salários mínimos mensais, 71,1\% exerciam suas funções há mais de um ano, com 97,5\% atuando em serviços da região urbana. Houve um total de 38 profissionais de saúde que se declararam tabagistas $(23,3 \%)$ e $43(26,4 \%)$ consumiam bebidas alcoólicas (Tabela 1).

Tabela 1. Variáveis sociodemográficas e de saúde.

\begin{tabular}{lrc}
\hline \multicolumn{1}{c}{ Variável } & n & Proporção (\%) \\
\hline Sexo & & \\
$\quad$ Feminino & 145 & 89,0 \\
$\quad$ Masculino & 18 & 11,0 \\
Faixa etária & & \\
$\quad$ 18 a 35 anos & 67 & 41,1 \\
$\quad$ Mais de 35 anos & 96 & 58,9 \\
Escolaridade & & \\
$\quad$ Fundamental & 35 & 21,5 \\
$\quad$ Médio ou técnico & 128 & 78,5 \\
Cor & & \\
$\quad$ Branca & 130 & 79,8 \\
$\quad$ Outra & 33 & 20,2 \\
Religião & & \\
$\quad$ Católica & 115 & 70,6 \\
$\quad$ Evangélica & 41 & 25,2 \\
$\quad$ Outra & 7 & 4,3 \\
\hline
\end{tabular}


Tabela 1. Variáveis sociodemográficas e de saúde.

\begin{tabular}{|c|c|c|}
\hline Variável & $\mathbf{n}$ & Proporção (\%) \\
\hline \multicolumn{3}{|l|}{ Situação conjugal } \\
\hline Não tem companheiro (a) & 36 & 22,1 \\
\hline Com companheiro (a) & 127 & 77,9 \\
\hline \multicolumn{3}{|l|}{ Residência } \\
\hline No bairro onde trabalha & 75 & 46,0 \\
\hline Outro & 88 & 54,0 \\
\hline \multicolumn{3}{|l|}{ Com quem reside } \\
\hline Com os pais & 34 & 20,9 \\
\hline Com outros familiares & 19 & 11,7 \\
\hline Com o cônjuge & 85 & 52,1 \\
\hline Sozinho & 19 & 11,7 \\
\hline Outros & 6 & 3,7 \\
\hline \multicolumn{3}{|l|}{ Tipo de trabalho } \\
\hline Saúde & 114 & 69,9 \\
\hline Administrativa & 28 & 17,2 \\
\hline Serviços Gerais & 21 & 12,9 \\
\hline \multicolumn{3}{|l|}{ Renda Familiar em Salários } \\
\hline \multicolumn{3}{|l|}{ Mínimos } \\
\hline Zero a três & 75 & 46,0 \\
\hline Quatro a cinco & 79 & 48,5 \\
\hline Mais de cinco & 9 & 5,5 \\
\hline \multicolumn{3}{|l|}{ Tempo de trabalho } \\
\hline 0 a 5 meses & 13 & 8,0 \\
\hline 6 meses a um ano & 34 & 20,9 \\
\hline 13 a 36 meses & 40 & 24,5 \\
\hline Mais de 3 anos & 76 & 46,6 \\
\hline \multicolumn{3}{|l|}{ Local de trabalho } \\
\hline Urbano & 159 & 97,5 \\
\hline Rural & 4 & 2,5 \\
\hline \multicolumn{3}{|l|}{ Tabagismo } \\
\hline Sim & 38 & 23,3 \\
\hline Não & 125 & 76,7 \\
\hline \multicolumn{3}{|l|}{ Uso de bebidas alcoólicas } \\
\hline Sim & 43 & 26,4 \\
\hline Não & 120 & 73,6 \\
\hline \multicolumn{3}{|l|}{$\begin{array}{l}\text { Estar em tratamento de } \\
\text { saúde }\end{array}$} \\
\hline Sim & 25 & 15,3 \\
\hline Não & 138 & 84,7 \\
\hline \multicolumn{3}{|l|}{$\begin{array}{l}\text { Uso regular de } \\
\text { medicamentos }\end{array}$} \\
\hline Sim & 55 & 33,7 \\
\hline Não & 108 & 66,3 \\
\hline
\end{tabular}

O questionário Estereótipos de Gênero apresentou um escore médio de 15,07; que corresponde a 53,8\% do maior escore possível (Tabela 2). Dois de seus itens obtiveram uma pontuação inferior a 50,0\% do possível. Estas questões eram referentes à possibilidade de o homem exercer mal tratos e agressão física. Cinco apresentaram um escore mais elevado do que metade dos pontos possíveis e duas destas superiores a 70\% e correspondiam a afirmativas de que os homens ao se interessarem por mulheres buscam sexo e de que as mulheres procuram romance. No Inventário de Sexismo Ambivalente (Tabelas 2, 3 e 4) o componente Hostil obteve média de 32,03 (58,2\% do valor mais alto). A grande maioria dos itens desta dimensão apresentaram escore maior que a metade da pontuação possível, a única exceção foi a que afirmava que as mulheres interpretavam expressões inocentes como sexistas, dando como exemplo deste tipo de enunciado "as vezes é certo um homem bater em uma mulher”. A que obteve maior número de pontos $(73,7 \%)$ era a que colocava que as mulheres se "insinuam sensualmente para os homens e depois rejeitam seus avanços ou 'cantadas". As demais ficaram entre 50 e $70 \%$. A dimensão Benévola apresentou o escore médio de 35,23 de média $(64,1 \%$ da pontuação). Houve sete questões que ultrapassaram $60 \%$ dos valores máximos. Destas, quatro ultrapassaram 70,0\%. Somente uma que foi inferior a 50,0\% ("Em caso de grandes ou pequenos acidentes, as mulheres devem ser resgatadas antes que os homens").

A Tabela 3 mostra que ao se calcular os escores estratificados do Sexismo Hostil por variáveis sociodemográficas, "ser de outra religião" (diferente da católica ou evangélicas) foi a que obteve menor escore médio com $49,6 \%$ da pontuação possível. $\mathrm{O}$ valor mais alto encontrado foi para os que cursaram apenas o Ensino Fundamental, com 67,3\% do escore máximo, para Sexismo Benévolo. Com exceção da variável já citada, todos os escores médios, quando categorizados por variáveis sociodemográficas mostraram valores acima de 50,0\% da pontuação máxima.

A Tabela 5 indica que Estereótipos de Gênero não se associou de maneira significante a nenhuma das variáveis sociodemográficas e de saúde.

Sexismo Hostil (Tabela 4) estava associado a Sexo ( $p<0,001)$, com os homens apresentando um escore superior ao das mulheres. Quando se estratificou esta variável por sexo e raça, encontrou-se que os homens brancos tiveram um escore médio $(37,1 ; \mathrm{DP}=7,3)$ maior que o das mulheres brancas $(31,5 ; \mathrm{DP}=5,8)$; achado que foi estatisticamente significante $(\mathrm{p}=0,01)$. Não brancos também apresentaram médias mais elevadas entre os homens ( $\mathrm{p}=0,03)$. Não se encontrou diferenças significantes ao se comparar homens brancos com não brancos, nem ao se fazer 
Tabela 2. Escore médio e porcentagem do escore máximo por variável em Estereótipos de Gênero e Inventário do Sexismo Ambivalente.

\begin{tabular}{|c|c|c|c|}
\hline Instrumento e Questões & Escore & $\begin{array}{l}\% \text { da } \\
\text { Média }\end{array}$ & Mediana \\
\hline Estereótipo de Gênero & 15,07 & 53,8 & 15,0 \\
\hline 1. A maioria das mulheres gosta de ser maltratada por homens. & 1,48 & 37,1 & 1,0 \\
\hline 2. A maioria das mulheres gosta de exibir seus corpos. & 2,70 & 67,5 & 3,0 \\
\hline 3. A maioria dos homens quer sair com mulheres apenas para fazer sexo. & 2,85 & 71,3 & 3,0 \\
\hline 4. A maioria das mulheres gosta de casos românticos com homens. & 2,94 & 73,5 & 3,0 \\
\hline 5. A maioria das mulheres depende dos homens para se livrarem de encrencas. & 2,22 & 55,5 & 2,0 \\
\hline 6. Ás vezes está certo um homem bater em sua mulher. & 1,39 & 34,8 & 1,0 \\
\hline 7. Homens e mulheres deveriam ter igual responsabilidade pela criação de filhos. & 1,48 & 63,0 & 1,0 \\
\hline \multicolumn{4}{|l|}{ Inventário de Sexismo Ambivalente } \\
\hline Sexismo Hostil & 32,03 & 58,2 & 32,0 \\
\hline Sexismo Benévolo & 35,23 & 64,1 & 36,0 \\
\hline $\begin{array}{l}\text { 1. Ainda que um homem tenha muito êxito em sua vida, não poderá sentir-se } \\
\text { completo a menos que tenha o amor de uma mulher. }\end{array}$ & 3,36 & 67,2 & 4,0 \\
\hline $\begin{array}{l}\text { 02. Com o pretexto da igualdade, muitas mulheres buscam privilégios especiais, } \\
\text { como condições de trabalho que as favoreçam. }\end{array}$ & 3,15 & 63,1 & 3,0 \\
\hline $\begin{array}{l}\text { 03. Em caso de grandes ou pequenos acidentes, as mulheres devem ser resgatadas } \\
\text { antes que os homens. }\end{array}$ & 2,45 & 49,1 & 2,0 \\
\hline $\begin{array}{l}\text { 04. A maioria das mulheres interpreta os comentários ou brincadeiras inocentes } \\
\text { como sexistas, isto é, como expressões preconceituosas ou discriminatórias } \\
\text { contra elas como: Às vezes está certo um homem bater em sua mulher. }\end{array}$ & 2,37 & 47,5 & 2,0 \\
\hline 05. As mulheres se ofendem muito facilmente. & 3,33 & 66,5 & 4,0 \\
\hline $\begin{array}{l}\text { 06. As pessoas não podem ser verdadeiramente felizes em suas vidas a menos que } \\
\text { tenham uma outra pessoa do sexo oposto. (Ex.: para o homem, uma mulher, e } \\
\text { vice-versa). }\end{array}$ & 2,60 & 51,9 & 2,0 \\
\hline $\begin{array}{l}\text { 07. Na verdade, o que as mulheres feministas pretendem é que a mulher tenha } \\
\text { mais poder que o homem. }\end{array}$ & 2,83 & 56,6 & 2,0 \\
\hline $\begin{array}{l}\text { 08. Muitas mulheres se caracterizam por uma pureza que poucos homens } \\
\text { possuem. }\end{array}$ & 3,37 & 67,5 & 4,0 \\
\hline 09. As mulheres devem ser queridas e protegidas pelos homens. & 3,99 & 79,8 & 4,0 \\
\hline $\begin{array}{l}\text { 10. A maioria das mulheres não dá valor de forma completa a tudo o que os } \\
\text { homens fazem por ela. }\end{array}$ & 2,91 & 58,3 & 3,0 \\
\hline 11. As mulheres tentam ganhar poder controlando os homens. & 2,69 & 53,9 & 2,0 \\
\hline 12. Todo homem deve ter uma mulher a quem amar. & 3,57 & 71,4 & 4,0 \\
\hline 13. O homem está incompleto sem a mulher. & 3,19 & 63,8 & 4,0 \\
\hline 14. As mulheres exageram os problemas que têm no trabalho. & 2,63 & 52,6 & 2,0 \\
\hline $\begin{array}{l}\text { 15. Uma vez que uma mulher consiga que o homem se comprometa com ela, } \\
\text { geralmente, ela tenta o controlar. }\end{array}$ & 2,89 & 57,8 & 3,0 \\
\hline $\begin{array}{l}\text { 16. Quando as mulheres são vencidas pelos homens numa disputa justa, } \\
\text { geralmente elas se queixam de haver sido "roubadas" ou discriminadas. }\end{array}$ & 2,78 & 55,6 & 2.0 \\
\hline 17. Uma boa mulher deveria ser posta em um pedestal pelo homem. & 2,96 & 59,3 & 2,0 \\
\hline $\begin{array}{l}\text { 18. Existem muitas mulheres que, para chamar a atenção de um homem, } \\
\text { primeiro se insinuam sensualmente e depois rejeitam seus avanços ou 'cantadas'. }\end{array}$ & 3,69 & 73,7 & 4,0 \\
\hline $\begin{array}{l}\text { 19. As mulheres, em comparação com os homens, tendem a ter uma maior } \\
\text { sensibilidade moral. }\end{array}$ & 3,51 & 70,2 & 4,0 \\
\hline $\begin{array}{l}\text { 20. Os homens deveriam estar dispostos a sacrificar seu próprio bem-estar a fim } \\
\text { de dar segurança econômica e social às mulheres. }\end{array}$ & 2,70 & 54,0 & 2,0 \\
\hline $\begin{array}{l}\text { 21. As mulheres feministas estão fazendo exigências completamente irracionais } \\
\text { aos homens. }\end{array}$ & 2,75 & 55,1 & 3,0 \\
\hline $\begin{array}{l}\text { 22. As mulheres, em comparação com os homens, mostram um sentido mais } \\
\text { refinado para a cultura e o bom gosto. }\end{array}$ & 3,53 & 70,6 & 4,0 \\
\hline
\end{tabular}

A questão 7 de Estereótipos de Gênero é contada de forma invertida. Sexismo hostil: 2, 4, 5, 7, 10, 11, 14, 15, 16, 18, 21. Sexismo benévolo: 1, 3, 6, 8, 9, 12, 13, 17, 19, 20, 22. 
Tabela 3. Escores Médios e percentual do escore máximo em Estereótipos de Gênero, Sexismo Hostil e Sexismo Benevolente por variáveis sociodemográficas e de saúde.

\begin{tabular}{|c|c|c|c|c|c|c|}
\hline \multirow{2}{*}{ Variável } & \multicolumn{2}{|c|}{ Estereótipo de gênero } & \multicolumn{2}{|c|}{ Sexismo Hostil } & \multicolumn{2}{|c|}{ Sexismo Benévolo } \\
\hline & Média & $\%$ & Média & $\%$ & Média & $\%$ \\
\hline \multicolumn{7}{|l|}{ Sexo } \\
\hline Feminino & 15,02 & 53,6 & 31,41 & 57,1 & 35,41 & 64,4 \\
\hline Masculino & 15,44 & 55,1 & 37,06 & 67,4 & 33,78 & 61,4 \\
\hline \multicolumn{7}{|l|}{ Faixa etária } \\
\hline 18 a 35 anos & 15,1 & 53,9 & 32,67 & 59,4 & 35,82 & 65,1 \\
\hline Mais de 35 anos & 15,04 & 53,7 & 31,58 & 57,4 & 34,82 & 63,3 \\
\hline \multicolumn{7}{|l|}{ Escolaridade } \\
\hline Fundamental & 14,71 & 52,5 & 31,63 & 57,5 & 37,03 & 67,3 \\
\hline Médio ou técnico & 15,16 & 54,1 & 32,14 & 58,4 & 34,74 & 63,2 \\
\hline \multicolumn{7}{|l|}{ Cor } \\
\hline Branca & 14,98 & 53,5 & 31,97 & 58,1 & 35,22 & 64,0 \\
\hline Outra & 15,39 & 55,0 & 32,27 & 58,7 & 35,27 & 64,1 \\
\hline \multicolumn{7}{|l|}{ Religião } \\
\hline Católica & 14,97 & 53,5 & 31,86 & 57,9 & 34,96 & 63,6 \\
\hline Evangélica & 15,39 & 55,0 & 33,32 & 60,6 & 36,76 & 66,8 \\
\hline Outra & 14,86 & 53,1 & 27,29 & 49,6 & 30,86 & 56,1 \\
\hline \multicolumn{7}{|l|}{ Situação conjugal } \\
\hline Não tem companheiro (a) & 14,51 & 51,8 & 32,5 & 59,1 & 34,97 & 63,6 \\
\hline Com companheiro (a) & 15,2 & 54,3 & 31,9 & 58,0 & 35,31 & 64,2 \\
\hline \multicolumn{7}{|l|}{ Residência } \\
\hline No bairro onde trabalha & 15,44 & 55,1 & 33,12 & 60,2 & 35,88 & 65,2 \\
\hline Outro & 14,75 & 52,7 & 31,1 & 56,5 & 34,68 & 63,1 \\
\hline \multicolumn{7}{|l|}{ Com quem reside } \\
\hline Com o cônjuge & 15,02 & 53,6 & 31,78 & 57,8 & 35,27 & 64,1 \\
\hline Sozinho ou com outros & 15,12 & 54,0 & 32,31 & 58,7 & 35,19 & 64,0 \\
\hline \multicolumn{7}{|l|}{ Tipo de trabalho } \\
\hline Saúde & 15,11 & 54,0 & 31,94 & 58,1 & 35,06 & 63,7 \\
\hline Administrativa & 15,32 & 54,7 & 33,25 & 60,5 & 35,57 & 64,7 \\
\hline Serviços Gerais & 14,52 & 51,9 & 30,9 & 56,2 & 35,71 & 64,9 \\
\hline \multicolumn{7}{|c|}{ Renda Familiar em Salários Mínimos } \\
\hline Zero a três & 15,23 & 54,4 & 32,25 & 58,6 & 36 & 65,5 \\
\hline Quatro a cinco & 14,9 & 53,2 & 31,71 & 57,7 & 34,72 & 63,1 \\
\hline Mais de cinco & 15,22 & 54,4 & 33 & 60,0 & 33,33 & 60,6 \\
\hline
\end{tabular}

o mesmo entre as mulheres. O Sexismo Hostil também se associou significantemente a Religião, sendo que os evangélicos foram os mais sexistas hostis, vindo em seguida católicos e, por último, outras $(p=0,048)$. Este tipo de comportamento também predominou de maneira significante $(\mathrm{p}$ $=0,025)$ entre os usuários de bebidas alcoólicas $($ escore $=33,84)$ em relação aos demais trabalhadores (escore $=31,38$ ). Outras variáveis como faixa etária, escolaridade, cor referida, situação conjugal, residência com o cônjuge, tipo de função no serviço de saúde, renda, tempo de serviço, 


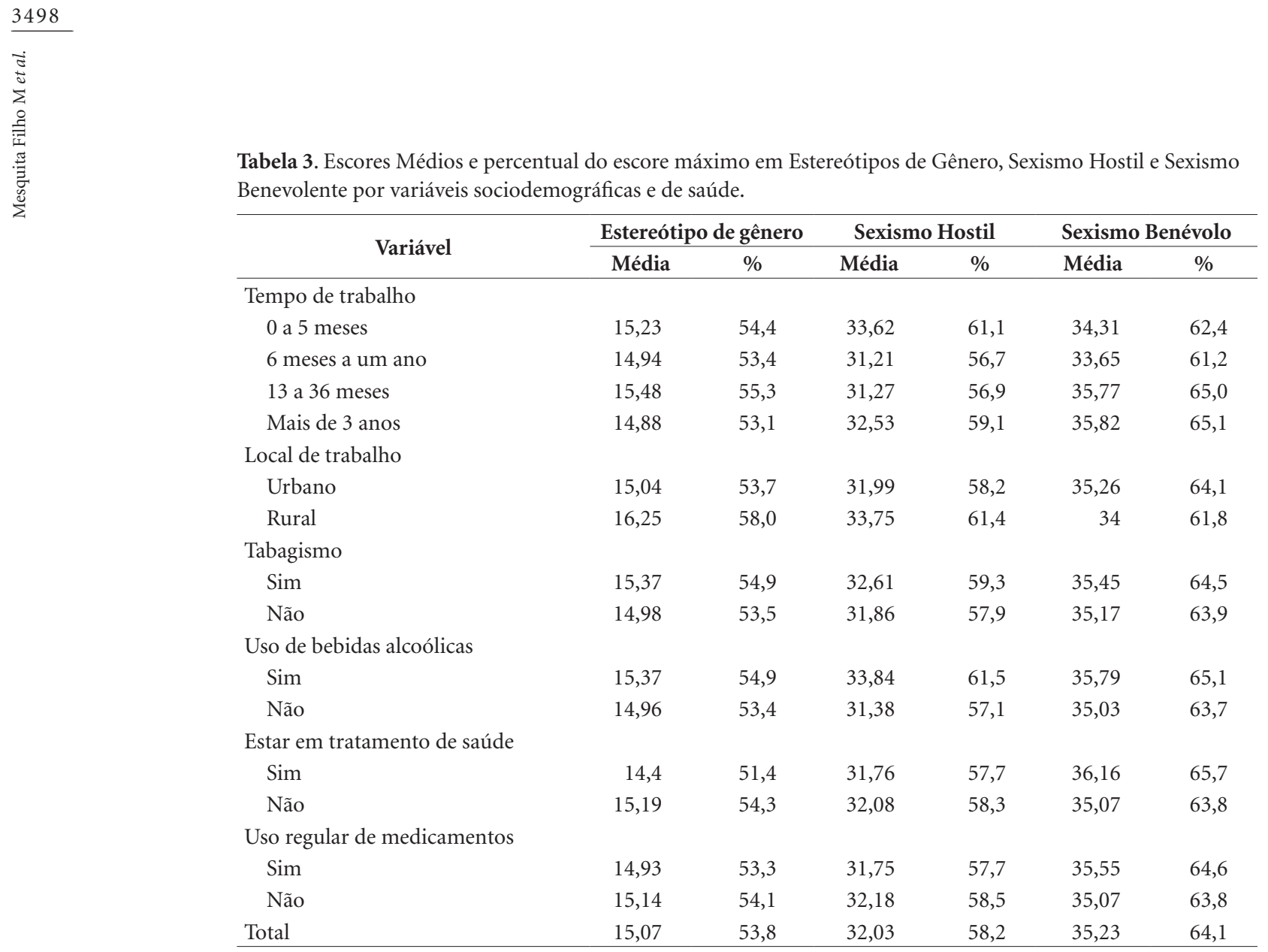

\section{Discussão}

O perfil sociodemográfico dos componentes da amostra deste estudo correspondeu às características de profissionais de APS encontradas em outros trabalhos ${ }^{26,27}$.

As três escalas usadas (Estereótipos de Gênero, Sexismo Hostil e Sexismo Benévolo) não têm pontos de corte definidos. Os autores informam que quanto mais alta a pontuação, mais preconceitos existem. Nesta pesquisa, todas elas se apresentaram elevadas, indicando a existência do preconceito contra a mulher entre os trabalhadores em saúde. O componente Benevolente do Sexismo foi o que apresentou médias mais elevadas. Isso aconteceu, possivelmente, pelo fato dele se apresentar como "atitude positiva, aparentemente não preconceituosa em relação à mulher, evidenciando o sentido paternalista que a descreve como pessoa frágil, que necessita atenção, mas que também pode complementar o homem" ${ }^{28}$. Os efeitos nefastos do sexismo hostil são incontestáveis, entretanto, há menor reconhecimento social das consequências negativas do sexismo benevolente.
Ao se estudar especificamente Estereótipos de Gênero, não foram encontradas diferenças estatisticamente significantes ao se estratificar os escores obtidos em cada item pelas variáveis sociodemográficas. Entretanto, estes estereótipos estavam presentes, pois a pontuação obtida era elevada (mais que 50,0\% dos seus valores máximos, exceto para uma variável), não importando a estratificação que fosse efetuada. Sexismo e Estereótipos de Gênero aumentam o risco da violência contra a mulher ${ }^{6,28}$. No setor saúde, muitas vezes, acontecem abusos, maus tratos, negligência, abandono, atraso, desrespeito, quebra de confidencialidade, desconsideração da autonomia, realização de procedimentos dolorosos e desnecessários afetando mulheres ${ }^{29}$. Trabalhadores de saúde preconceituosos ao atuarem, podem trazer danos e prejuízos às usuárias dos serviços e a toda a organização do Sistema. Os profissionais, para desenvolverem ações efetivas e humanizadas e atuarem com interesse, diálogo, resolutividade, necessitam preparo para lidar com questões sociais e subjetivas presentes nas práticas do serviço. A Atenção Primária à Saúde e a Estratégia da Saúde da Família, são 
Tabela 4. Escores médios, mediana, desvio padrão e valor de p para Sexismo Hostil e para o Benévolo por variáveis sociodemográficas ou de saúde.

\begin{tabular}{|c|c|c|c|c|c|c|c|c|}
\hline \multirow[b]{2}{*}{ Variável } & \multicolumn{4}{|c|}{ Sexismo Hostil } & \multicolumn{4}{|c|}{ Sexismo Benévolo } \\
\hline & Média & $\begin{array}{l}\text { Desvio } \\
\text { padrão }\end{array}$ & Mediana & $\mathrm{p}$ & Média & $\begin{array}{l}\text { Desvio } \\
\text { padrão }\end{array}$ & Mediana & p \\
\hline Sexo & & & & $<0,001^{\star, \mathrm{ES}}$ & & & & $0,239^{*}$ \\
\hline Feminino & 31,41 & 5,83 & 31,00 & & 35,41 & 5,52 & 36,00 & \\
\hline Masculino & 37,06 & 6,68 & 37,00 & & 33,78 & 5,68 & 35,50 & \\
\hline Faixa etária & & & & $0,269^{*}$ & & & & $0,260^{*}$ \\
\hline 18 a 35 anos & 32,67 & 6,23 & 32,00 & & 35,82 & 5,45 & 37,00 & \\
\hline Mais de 35 anos & 31,58 & 6,11 & 31,00 & & 34,82 & 5,60 & 35,00 & \\
\hline Escolaridade & & & & $0,612^{*}$ & & & & $0,013^{* E S}$ \\
\hline Fundamental & 31,63 & 4,89 & 31,00 & & 37,03 & 4,36 & 37,00 & \\
\hline Médio ou técnico & 32,14 & 6,48 & 32,00 & & 34,74 & 5,75 & 35,00 & \\
\hline Cor & & & & $0,801^{\star}$ & & & & $0,964^{*}$ \\
\hline Branca & 31,97 & 6,15 & 31,50 & & 35,22 & 5,39 & 36,00 & \\
\hline Outra & 32,27 & 6,33 & 32,00 & & 35,27 & 6,22 & 38,00 & \\
\hline Religião & & & & $0,048^{\star *, \mathrm{ES}}$ & & & & $0,020^{\star * \mathrm{ES}}$ \\
\hline Católica & 31,86 & 5,76 & 32,00 & & 34,96 & 5,53 & 35,00 & \\
\hline Evangélica & 33,32 & 7,12 & 32,00 & & 36,76 & 4,93 & 37,00 & \\
\hline Outra & 27,29 & 4,11 & 27,00 & & 30,86 & 6,91 & 33,00 & \\
\hline Situação conjugal & & & & $0,606^{*}$ & & & & $0,750^{*}$ \\
\hline Não tem companheiro (a) & 32,50 & 6,39 & 33,00 & & 34,97 & 6,26 & 35,50 & \\
\hline Com companheiro (a) & 31,90 & 6,12 & 31,00 & & 35,31 & 5,35 & 36,00 & \\
\hline Com quem reside & & & & $0,584^{*}$ & & & & $0,929^{*}$ \\
\hline Com o cônjuge & 31,78 & 5,93 & 31,00 & & 35,27 & 5,30 & 36,00 & \\
\hline Sozinho ou com outros & 32,31 & 6,44 & 32,00 & & 35,19 & 5,83 & 35,50 & \\
\hline Tipo de trabalho & & & & $0,405^{\star *}$ & & & & $0,024^{* * \mathrm{ES}}$ \\
\hline Saúde & 31,94 & 6,13 & 36,00 & & 35,06 & 5,60 & 36,00 & \\
\hline Administrativa & 33,25 & 7,25 & 36,00 & & 35,57 & 5,90 & 36,00 & \\
\hline Serviços Gerais & 30,90 & 4,58 & 36,00 & & 35,71 & 4,97 & 36,00 & \\
\hline $\begin{array}{l}\text { Renda Familiar em Salários } \\
\text { Mínimos }\end{array}$ & & & & $0,767^{\star *}$ & & & & $0,207^{* *}$ \\
\hline Zero a três & 32,25 & 6,53 & 32,00 & & 36,00 & 5,29 & 37,00 & \\
\hline Quatro a cinco & 31,71 & 5,77 & 31,00 & & 34,72 & 5,67 & 35,00 & \\
\hline Mais de cinco & 33,00 & 6,93 & 32,00 & & 33,33 & 6,23 & 36,00 & \\
\hline Tempo de trabalho & & & & $0,468^{* *}$ & & & & $0,226^{* *}$ \\
\hline 0 a 5 meses & 33,62 & 7,02 & 33,00 & & 34,31 & 4,96 & 33,00 & \\
\hline 6 meses a um ano & 31,21 & 6,06 & 30,00 & & 33,65 & 6,28 & 34,50 & \\
\hline 13 a 36 meses & 31,27 & 5,29 & 31,50 & & 35,77 & 4,41 & 36,00 & \\
\hline Mais de 3 anos & 32,53 & 6,50 & 32,00 & & 35,82 & 5,76 & 36,00 & \\
\hline Local de trabalho & & & & $0,574^{\star}$ & & & & $0,654^{* *}$ \\
\hline Urbano & 31,99 & 6,17 & 32,00 & & 35,26 & 5,57 & 36,00 & \\
\hline Rural & 33,75 & 6,65 & 32,00 & & 34,00 & 4,76 & 32,00 & \\
\hline Tabagismo & & & & $0,513^{*}$ & & & & $0,787^{\star *}$ \\
\hline Sim & 32,61 & 7,14 & 31,00 & & 35,45 & 5,70 & 36,00 & \\
\hline Não & 31,86 & 5,86 & 32,00 & & 35,17 & 5,52 & 36,00 & \\
\hline Uso de bebidas alcoólicas & & & & $0,025^{\star, \mathrm{ES}}$ & & & & $0,444^{* *}$ \\
\hline Sim & 33,84 & 6,52 & 34,00 & & 35,79 & 5,43 & 36,00 & \\
\hline Não & 31,38 & 5,93 & 30,50 & & 35,03 & 5,60 & 36,00 & \\
\hline Total & 32,03 & 6,17 & 32,00 & & 35,23 & 5,55 & 36,00 & \\
\hline
\end{tabular}

${ }^{*}$ Teste $\mathrm{t} \quad{ }^{* *}$ ANOVA ${ }^{\mathrm{es}}$ Estatisticamente significante. 
Tabela 5. Escores médios, mediana, desvio padrão e valor de p para Estereótipos de Gênero por variáveis sociodemográficas ou de saúde.

\begin{tabular}{|c|c|c|c|c|}
\hline Variável & Média & Desvio padrão & Mediana & $\mathbf{p}$ \\
\hline Sexo & & & & $0,699^{*}$ \\
\hline Feminino & 15,02 & 2,51 & 15,00 & \\
\hline Masculino & 15,44 & 2,71 & 15,00 & \\
\hline Faixa etária & & & & $0,841^{\star}$ \\
\hline 18 a 35 anos & 15,10 & 2,00 & 15,00 & \\
\hline Mais de 35 anos & 15,04 & 2,85 & 15,00 & \\
\hline Escolaridade & & & & $0,102^{*}$ \\
\hline Fundamental & 14,71 & 3,21 & 15,00 & \\
\hline Médio ou técnico & 15,16 & 2,32 & 15,00 & \\
\hline Cor & & & & $0153^{\star}$ \\
\hline Branca & 14,98 & 2,52 & 15,00 & \\
\hline Outra & 15,39 & 2,59 & 15,00 & \\
\hline Religião & & & & $0,772^{\star *}$ \\
\hline Católica & 14,97 & 2,57 & 15,00 & \\
\hline Evangélica & 15,39 & 2,45 & 15,00 & \\
\hline Outra & 14,86 & 2,48 & 16,00 & \\
\hline Situação conjugal & & & & $0,699^{*}$ \\
\hline Não tem companheiro (a) & 14,51 & 2,99 & 15,00 & \\
\hline Com companheiro (a) & 15,20 & 2,38 & 15,00 & \\
\hline Residência & & & & $0,074^{\star}$ \\
\hline No bairro onde trabalha & 15,44 & 2,26 & 15,00 & \\
\hline Outro & 14,75 & 2,71 & 15,00 & \\
\hline Com quem reside & & & & $0,172^{\star}$ \\
\hline Com o cônjuge & 15,02 & 2,32 & 15,00 & \\
\hline Com outros & 15,12 & 2,75 & 15,00 & \\
\hline Tipo de trabalho & & & & $0,992^{* *}$ \\
\hline Saúde & 15,11 & 2,13 & 15,00 & \\
\hline Administrativa & 15,32 & 3,23 & 14,50 & \\
\hline Serviços Gerais & 14,52 & 3,40 & 16,00 & \\
\hline Renda Familiar em Salários Mínimos & & & & $0,477^{\star \star}$ \\
\hline Zero a três & 15,23 & 2,76 & 15,00 & \\
\hline Quatro a cinco & 14,90 & 2,36 & 15,00 & \\
\hline Mais de cinco & 15,22 & 1,99 & 15,00 & \\
\hline Tempo de trabalho & & & & $0,656^{\star *}$ \\
\hline 0 a 5 meses & 15,23 & 2,28 & 15,00 & \\
\hline 6 meses a um ano & 14,94 & 2,19 & 15,00 & \\
\hline 13 a 36 meses & 15,48 & 2,46 & 15,00 & \\
\hline Mais de 3 anos & 14,88 & 2,76 & 15,00 & \\
\hline Local de trabalho & & & & $0,204^{*}$ \\
\hline Urbano & 15,04 & 2,55 & 15,00 & \\
\hline Rural & 16,25 & 1,26 & 16,00 & \\
\hline Tabagismo & & & & $0,545^{\star}$ \\
\hline Sim & 15,37 & 2,66 & 15,00 & \\
\hline Não & 14,98 & 2,49 & 15,00 & \\
\hline Uso de bebidas alcoólicas & & & & $0,521^{\star}$ \\
\hline Sim & 15,37 & 2,74 & 15,00 & \\
\hline Não & 14,96 & 2,45 & 15,00 & \\
\hline Estar em tratamento de saúde & & & & $0,132^{*}$ \\
\hline Sim & 14,40 & 2,58 & 14,00 & \\
\hline Não & 15,19 & 2,51 & 15,00 & \\
\hline Uso rotineiro de medicamentos & & & & $0,774^{*}$ \\
\hline Sim & 14,93 & 2,43 & 15,00 & \\
\hline Não & 15,14 & 2,59 & 15,00 & \\
\hline Total & 15,07 & 2,53 & 15,00 & \\
\hline
\end{tabular}

${ }^{*}$ Teste de Mann-Whitney 
embasadas nos atributos de Acesso, Longitudinalidade, Integralidade, Coordenação, Competência Cultural $^{30}$, bem como, no Acolhimento e no Vínculo $^{31}$. Esses atributos se tornam impraticáveis na presença de Sexismo e Preconceito, ainda mais levando-se em conta que a maioria do público da APS é constituído por mulheres ${ }^{32}$.

É importante destacar a estratificação dos EG pela variável sexo. Tanto homens, como mulheres obtiveram escores elevados, sem diferença significativa entre eles. Este fato indica que ambos apresentam estereótipos quanto ao gênero. Estereótipos do feminino são mais comuns entre os homens, mas também pode ocorrer entre as mulheres $^{8,9}$. Tal achado pode estar indicando a possiblidade de discriminação das usuárias, mesmo em situações em que elas, quando buscassem o serviço de saúde, optassem por serem atendidas por profissionais do mesmo sexo.

Entretanto, é importante lembrar que a escala Estereótipos de Gênero é composta por apenas sete itens, insuficientes para avaliar toda complexidade deste construto. $\mathrm{O}$ instrumento produz resultados de precisão limitada, indicados para fins de triagem ${ }^{28}$, devendo ser discutidos com cautela.

Ao se estudar o Sexismo Hostil verificou-se que tanto os homens como as mulheres apresentavam pontuação indicativa da presença do preconceito. Entretanto, os homens foram significantemente mais hostis do que as mulheres.

Estudos mostram que preconceitos de gênero e raça se associam ${ }^{33,34}$. O fato de a maioria dos trabalhadores ser de cor branca poderia também estar contribuindo para a detecção do sexismo hostil em homens e mulheres. Entretanto, a estratificação dos escores do sexismo hostil por sexo e cor não mostrou diferenças entre homens brancos e não brancos, nem entre estes dois grupos nas mulheres. A detecção das inter-relações entre sexismo e racismo pode não ter ocorrido, neste estudo, devido à complexidade e multidimensionalidade deste construto ${ }^{34}$. Os instrumentos utilizados não estavam voltados à identificação destas questões. Outro fator que deve ser levado em conta é a composição étnica da população usuária dos serviços pesquisados. Provavelmente, ela era distinta da dos participantes da pesquisa, com uma maior proporção de não brancos, o que pode ter influenciado as respostas obtidas.

Houve diferenças significantes em relação ao sexismo hostil conforme a religião do profissional de saúde. Enquanto católicos e evangélicos tiveram escores elevados, indicando uma posição sexista hostil, os de outras religiões apresenta- ram uma média um pouco abaixo da metade dos pontos possíveis. As religiões têm sido apontadas como espaço de reprodução de relações sexistas e desiguais entre mulheres e homens, favorecendo sempre os últimos ${ }^{35}$. Mickolajczac e Pietrzak ${ }^{12}$ relacionaram a prática da religião católica com a presença do sexismo benévolo, mas não com a do hostil, diferentemente deste estudo. $\mathrm{Na}$ realidade brasileira, evangélicos e católicos, tradicionalmente, assumem valores conservadores em relação à família, sexualidade e costumes ${ }^{11}$. As religiões de inserção afro-brasileira apresentam um maior respeito aos valores e crenças dos seus seguidores $^{36,37}$.

Aqueles que tinham o hábito de consumir bebidas alcoólicas mostraram escores significativamente maiores para o Sexismo Hostil do que os não usuários. Este achado reforça o uso do álcool como fator desencadeante de episódios de sexismo hostil ${ }^{13,38}$. Ele também é associado à violência contra as mulheres ${ }^{39}$.

De todos os construtos, o Sexismo Benévolo foi o de escores mais elevados. No geral, a sua pontuação correspondeu, em média, a valores acima de $60,0 \%$ dos pontos possíveis.

Todas as categorias sociodemográficas, pelas pontuações apresentadas, podem ser consideradas Sexistas Benévolas. Entretanto, foram encontradas diferenças estatisticamente significativas em três delas: Escolaridade, Religião e Tipo de Trabalho. Não ocorreram diferenças entre homens e mulheres, fato observado em outros estu$\operatorname{dos}^{10,40}$. Como se discutiu nos outros construtos, ambos foram sexistas benévolos.

Quanto menor a escolaridade, maior foi o grau de sexismo benévolo ${ }^{10,41}$. Os trabalhadores de escolaridade fundamental foram significantemente mais preconceituosos que os de nível médio e/ou técnico.

O tipo de religião, como ocorreu no componente Hostil, também se associou à forma $\mathrm{Be}$ nevolente, só que com escores mais elevados. A maior pontuação dos católicos e dos evangélicos confirmaram a alta presença do Sexismo Benévolo nos grupos de orientação cristã em relação aos demais. Essa relação é geralmente mediada pelo apego ao conservadorismo, cujos valores se associam a visões do mundo presentes nas religiões cristãs $^{12}$.

Os trabalhadores, cujas práticas eram as de Atenção à Saúde, eram significantemente menos Sexistas Benévolos que os Administrativos e que os de Serviços Gerais. Tal fato pode estar associado à presença de uma maior escolaridade, ou por este tipo de profissional receber maiores ofertas 
de reciclagens e treinamentos, bem como por terem uma atuação direta junto ao usuário, o que poderia trazer-lhes motivações mais humanísticas. Entretanto, apesar da diferença estatística, todos eles apresentaram escores elevados, superiores a $60,0 \%$ dos pontos possíveis. O primeiro contato que uma usuária tem ao chegar em um serviço de APS é, geralmente, com técnicos e auxiliares de enfermagem, que costumam ser os responsáveis pelo acolhimento. Entretanto, existem situações em que tal função é desempenhada por funcionário administrativo. Nos dois casos, se a demanda de quem procura o serviço for potencialmente desencadeante do preconceito e se quem a atende for sexista, atitudes contrárias ao direito à saúde, ao atendimento humanizado, ao respeito ao usuário podem ocorrer.

\section{Limitações do estudo}

Este trabalho apresentou algumas limitações. Os construtos pesquisados ao serem assumidos publicamente, podem resultar em reprovação e constrangimento. Alguns trabalhadores, para que não fossem taxados de preconceituosos, por vezes poderiam optar por não responder aos instrumentos com o que realmente pensavam, pois, a atitude sexista é socialmente condenada e pode ocasionar restrições. Pesquisas a respeito de comportamentos reprováveis, ilegais ou marginais, têm a possibilidade de gerar resultados imprecisos e vieses em suas estatísticas. Entretanto, na literatura existem poucas pesquisas sobre formas de reduzir estas limitações. Para sua minimização, os pesquisadores, antes da aplicação dos instrumentos, além de efetuarem a completa explicação dos objetivos e metodologia da pesquisa, colocavam detalhadamente a garantia de confidencialidade. Além disso, os questionários eram auto preenchidos, em local tranquilo e sem circulação de pessoal, sempre individualmente, prevenindo-se a intimidação e constrangimento do respondente, fosse por quem aplicasse o instrumento ou por quaisquer outras pessoas que ensejassem o possível falseamento das respostas. A estes cuidados acrescentou-se, entre os procedimentos de análise estatística, o cálculo do alfa de Crömbach, para mensuração da confiabilidade.

Por ter sido realizado em município de médio porte, situado no Sudeste do Brasil, a generalização dos resultados foi feita com cautela, pois a questão do preconceito contra a mulher pode se apresentar de maneiras diferentes nas diversas regiões do país. Alguns fatores que não foram considerados como a experiência de cada profissional de saúde, sua capacitação, reciclagens, poderiam acrescentar maiores informações aos resultados. Além disso, por se tratar de tema pouco pesquisado, foram encontrados poucos trabalhos que propiciassem comparações diretas aos resultados.

\section{Conclusões}

Os resultados deste trabalho apontam que os profissionais de saúde portavam Estereótipos de Gênero, Sexismo Hostil e Benevolente. Eles se associaram a variáveis que mostraram que estes fenômenos se inseriram em situações sociais que extrapolam os serviços de saúde e são questões que devem ser enfrentadas por toda a sociedade.

Nos serviços de saúde, a existência de preconceito contra a mulher é inaceitável em qualquer circunstância. A sua ocorrência nas práticas da Atenção Primária em Saúde não é admissível, pois agrava as iniquidades já existentes. Os próprios trabalhadores podem se tornar causadores de problemas. Indivíduos sexistas, estereotipados, não são capazes de desempenhar o papel ético de proteção a usuários do SUS, não cumprindo sua função de "proteger seres e entes vivos contra ameaças que podem prejudicar de maneira irreversível suas existências" ${ }^{\text {42. }}$. Populações de mulheres, vítimas de violência ou de outros agravos, estarão expostas a atitudes danosas, hostis, com prejuízos nas esferas mental, física, moral, espiritual e de cidadania.

Os achados deste estudo levantam a possibilidade de novas pesquisa. Novos aspectos do problema poderão ser levantados dando-se voz às usuárias ou ainda, abordando questões sobre as práticas de saúde desenvolvidas, a existência ou não da educação continuada, relações de trabalho, inserção social entre outros, aprofundando as questões aqui discutidas.

Políticas públicas antissexistas, que levem em conta a área da saúde, devem ser estabelecidas a curto prazo, envolvendo a condenação de atitudes preconceituosas de forma cotidiana, bem como, ações de educação continuada para os trabalhadores da área. 


\section{Colaboradores}

M Mesquita Filho trabalhou na concepção e delineamento do estudo, na análise e interpretação dos dados, na redação do artigo; na revisão crítica do artigo e na aprovação da versão a ser publicada. ABC Rocha, MB Brito, SR Oliveira e TF Marques trabalharam na concepção e no delineamento do estudo, na coleta, análise e interpretação dos dados. CCQ Pereira trabalhou na redação do artigo, revisão crítica do artigo e na aprovação da versão a ser publicada.

\section{Referências}

1. World Health Organization (WHO). Global and regional estimates of violence against women: prevalence and health effects of intimate partner violence and nonpartner sexual violence. Genebra: WHO; 2013.

2. Stuber J, Meyer I, Link B. Stigma, prejudice, discrimination and health. Soc Sci Med 2008; 67(3):351-357.

3. Brasil. Ministério da Saúde (MS). Política nacional de atenção integral à saúde da mulher: princípios e diretrizes. Brasília: MS; 2004.

4. Araújo LM, Penna LHG. A relação entre sexo, identidades sexual e de gênero no campo da saúde da mulher. Rev enferm UERJ 2014; 22(1):134-138.

5. Franzoi NM, Fonseca RMGS, Guedes RN. Violência de gênero: concepções de profissionais das equipes de saúde da família. Rev. Latino-Am. Enfermagem 2011; 19(3):589-597.

6. Formiga NS. Valores humanos e sexismo ambivalente. Rev. Dep. Psicol. 2007; 19(2):381-396.

7. Guedes RN, Silva ATMC, Coelho EAC. Violência conjugal: problematizando a opressão das mulheres vitimizadas sob olhar de gênero. Rev Eletr Enferm 2007; 9(2):362-378.

8. Guimarães ASA. O insulto racial: as ofensas verbais registradas em queixas de discriminação. Estud. afro-asiát. 2000; 38:31-48.

9. Wilson BL, Diedrich A, Phelps CL, Choi M. Bullies at work: The impact of horizontal hostility in the hospital setting and intent to leave. J Nurs Adm 2011; 41(11):453-458.

10. Moyano M, Expósito F, Trujillo HM. Cierre cognitivo, sexismo y religiosidad: diferencias y similitudes entre grupos de adolescentes con distinta cultura. Anal. Psicol. 2013; 29(2):501-508.

11. Parga EJS, Sousa JHM, Costa, MC. Estereótipos e preconceitos de gênero entre estudantes de enfermagem da UFBA. Revista Baiana de Enfermagem 2001; 14(1):111-118.

12. Mikołajczak M, Pietrzak J. Ambivalent Sexism and Religion: Connected Through Values. Sex Roles 2014; 70(9-10):387-399.

13. Souza TMS. Assédio moral e assédio sexual: interfaces. Revista de Gestão Integrada em Saúde do Trabalho e Meio Ambiente 2008; 3(3):1-11.

14. Fonseca RMGS. Eqüidade de gênero e saúde das mulheres. Rev Esc Enferm USP 2005; 39(4):450-459.

15. Benites APO, Barbarini N. Histórias de vida de mulheres e saúde da família: algumas reflexões sobre gênero. Psicol. Soc. 2009; 21(1):16-24.

16. Herrera C, Agoff C. Dilemas del personal médico ante la violencia de pareja en México. Cad Saude Publica 2006; 22(11):2349-2357.

17. Ayanian JZ, Epstein AM. Differences in the use of procedures between women and men hospitalized for coronary artery disease. N Engl J Med 1991; 325(4):221225.

18. Ayanian JZ, Weissman JS, Chasan-Taber S, Epstein AM. Quality of care by race and gender for congestive heart failure and pneumonia. MedCare 1999; 37(12):12601269.

19. Brasil. Ministério da Saúde (MS). Programa Saúde da Família. Rev Saude Publica 2000; 34(3):316-319. 
20. Saliba O, Garbin CAS, Garbin AJI, Dossi AP. Responsabilidade do profissional de saúde sobre a notificação de casos de violência doméstica. Rev Saude Publica 2007; 41(3):472-477.

21. Gunter B, Wober M. Television viewing and perceptions of women's roles on television and in real life. Current Psychological Research 1982; 2(1-3):277-287.

22. Foshee VA, Bauman KE. Gender stereotyping and adolescent sexual behavior: a test of temporal order. Journal of Applied Social Psychology 1992; 22(20):15611579.

23. Eufrásio C. Tradução, adaptação cultural e validação do questionário Gender Stereotyping [dissertação]. Pouso Alegre: Universidade do Vale do Sapucaí; 2007.

24. Glick P, Fiske ST, Mladinic A, Saiz JL, Abrams D, Masser B, Adetoun B, Osagie JE, Akande A, Alao A, Brunner A, Willemsen TM, Chipeta K, Dardenne B, Dijksterhuis A, Wigboldus D, Eckes T, Six-Materna I, Expósito F, Moya M, Foddy M, Kim HJ, Lameiras M, Sotelo MJ, Mucchi-Faina A, Romani M, Sakalli N, Udegbe B, Yamamoto M, Ui M, Ferreira MC, López López W. Beyond prejudice as simple antipathy: Hostile and benevolent sexism across cultures. J Pers Soc Psychol 2000; 79(5):763-775.

25. Formiga NS, Gouveia VV, Santos MN. Inventário de sexismo ambivalente: sua adaptação e relação com o gênero. Psicologia em Estudo 2002; 7(1):105-111.

26. Tomasi E, Facchini LA, Piccini RX, Thumé E, Silveira DS, Siqueira FV, Rodrigues MA, Paniz VV, Teixeira VA. Perfil sócio-demográfico e epidemiológico dos trabalhadores da atenção básica à saúde nas regiões Sul e Nordeste do Brasil. Cad Saude Publica 2008; 24(Supl. 1):s193-s201.

27. Cotta RMM, Schott M, Azeredo CM, Franceschini SCC, Priore SE, Dias G. Organização do trabalho e perfil dos profissionais do Programa Saúde da Família: um desafio na reestruturação da atenção básica em saúde. Epidemiol. Serv. Saúde 2006; 15(3):7-18.

28. Mesquita Filho M, Eufrásio C. Estereótipos de Gênero e Sexismo Ambivalente em Adolescentes Masculinos de 12 a 16 Anos. Saúde Soc. 2011: 20(3):554-567.

29. Vogel JP, Bohren MA, Tunçalp O, Oladapo OT, Adanu RM, Baldé MD, Maung TM, Fawole B, Adu-Bonsaffoh K, Dako-Gyeke P, Maya ET, Camara MC, Diallo AB, Diallo S, Wai KT, Myint T, Olutayo L, Titiloye M, Alu F, Idris H, Gülmezoglu MA; WHO Research Group on the Treatment of Women During Childbirth. How women are treated during facility-based childbirth: development and validation of measurement tools in four countries - phase 1 formative research study protocol. Reprod Health 2015; 12:60.
30. Starfield B. Atenção primária: equilíbrio entre necessidades de saúde, serviços e tecnologia. Brasília: Unesco, Ministério da Saúde; 2002.

31. Coelho MO, Jorge MSB. Tecnologia das relações como dispositivo do atendimento humanizado na atenção básica à saúde na perspectiva do acesso, do acolhimento e do vínculo. Cien Saude Colet 2009; 14(Supl. 1):1523-1531.

32. Fernandes LCL, Bertoldi AD, Barros AJD. Utilização dos serviços de saúde pela população coberta pela Estratégia de Saúde da Família. Rev Saude Publica 2009; 43(4):595-603.

33. Carneiro S. Mulheres em movimento. Estudos Avançados 2003; 17(49):117-132.

34. Kerner I. Tudo é interseccional? Sobre a relação entre racismo e sexismo. Novos Estudos 2012; 93:45-58.

35. Bohn SR. Evangélicos no Brasil. Perfil socioeconômico, afinidades ideológicas e determinantes do comportamento eleitoral. Opinião Pública 2004; 10(2):288-338.

36. Prandi R. As religiões afro-brasileiras e seus seguidores. Civitas 2003; 3(1):15-33.

37. Silva VG. Neopentecostalismo e religiões afro-brasileiras: Significados do ataque aos símbolos da herança religiosa africana no Brasil contemporâneo. Mana 2007; 13(1):207-236.

38. Prado MAM, Queiroz IS. A emergência da politização da intimidade na experiência de mulheres usuárias de drogas. Estudos de Psicologia 2012; 17(2):305-312.

39. Deslandes SF, Gomes R, Silva CMFP. Caracterização dos casos de violência doméstica contra a mulher atendidos em dois hospitais públicos do Rio de Janeiro. Cad Saude Publica 2000; 16(1):129-137.

40. Recio P, Cuadrado I, Ramos E. Propiedades psicométricas de la Escala de Detección de Sexismo en Adolescentes (DSA). Psicothema 2007; 19(3):522-528.

41. Fernández ML, Castro YR. Evaluación del sexismo ambivalente en estudiantes gallegos/as. Acción psicológica 2003; 2(2):131-136.

42. Schramm FR. Bioética da Proteção: ferramenta válida para enfrentar problemas morais na era da globalização. Revista Bioética 2008; 16(1):11-23.

Artigo apresentado em 14/03/2016

Aprovado em 28/02/2017

Versão final apresentada em 02/03/2017 